\title{
The Third International Inflammatory Breast Cancer Conference
}

\author{
Kenneth $L$ van Golen ${ }^{1,2}$ and Massimo Cristofanilli ${ }^{3 *}$
}

\begin{abstract}
Inflammatory breast cancer (IBC) is the most aggressive and deadly form of breast cancer. Disease-specific research and conferences have been organized since 2008 with the intent to bring together experts in various disciplines. This report focus on the Third International IBC Conference held in Philadelphia on December 2012.
\end{abstract}

\section{Meeting goals}

The Third International Inflammatory Breast Cancer Conference, held on 1-2 December 2012 in Philadelphia, was an opportunity to gather physicians and scientists dedicated to the study and treatment of patients affected by this aggressive form of breast cancer. The meeting objectives included an education on the peculiar clinical and molecular aspects of inflammatory breast cancer (IBC) and discussion of the latest developments in clinical care and translational research. IBC is arguably the most aggressive form of breast cancer and is often misdiagnosed as an infection [1]. The disease is a phenotypically distinct and unique disease compared to other forms of breast cancer [2]. The meeting was attended by 137 participants representing eight countries.

\section{Meeting sessions}

The opening session began with welcoming remarks and an introduction about the importance of the conference in providing guidelines regarding the course of future research, including the investigation of novel treatments with potential impact on patients' outcome. Distinguished speakers Margaret Foti (American Association for Cancer Research), Francis Visco (National Breast Cancer Coalition), Elaine Grobman (Philadelphia Affiliate of Susan G Komen

\footnotetext{
* Correspondence: Massimo.Cristofanilli@jefferson.edu

${ }^{3}$ Department of Medical Oncology, Thomas Jefferson University, Kimmel Cancer Center, 1025 Walnut St-Suite 700, Philadelphia, PA 19107, USA Full list of author information is available at the end of the article
}

for the Cure) and Senator Timothy Z Jennings of the New Mexico State Senate took part in the opening session.

The plenary lecture was delivered by Chi Van Dang (Abramson Cancer Center, University of Pennsylvania, USA) and provided an overview of the evolving concepts regarding the role of the $m y c$ oncogene in regulating tumor metabolism [3]. The first scientific session was dedicated to the epidemiological aspects of IBC. Paul Levine (George Washington University School of Medicine, Washington, DC, USA) gave an overview of what is known about IBC epidemiology, including a discussion of recently identified clusters of new cases in various parts of the United States, strongly suggesting a potential environmental factor in the etiology of the disease [4]. The session included the presentation of two original studies selected from among the submitted abstracts for their original contribution. Hugo Arias-Pulido (University of New Mexico Cancer Center, USA) presented a retrospective study conducted in collaboration with investigators in Algeria, North Africa, demonstrating the detection of mouse mammary tumor virus-like sequences in mastectomy specimens from patients with IBC. Arias-Pulido's work suggests the possibility of a potential link between the disease and exposure to mouse mammary tumor virus, which requires further confirmatory investigation. The second study was presented by Catherine Schairer (The National Cancer Institute, Bethesda, Maryland, USA) and focused on risk factors pertaining to IBC and advanced breast cancers [5]. Schairer's study included a comparison of a very large cohort of IBC and non-IBC patients and looked at factors that included family history, body mass index, education and age at first birth. The results of the study demonstrate varying risk factors that suggest a distinct etiology of IBC.

The opening day ended with an advocate session and presentations by representatives of the Inflammatory Breast Cancer Foundation, The IBC Network, the Inflammatory Breast Cancer Research Foundation and the Triple Negative Breast Cancer Foundation.

The second day opened with a session dedicated to breaking news in IBC research update. The opening 
lecture was given by Patricia S Steeg (The National Cancer Institute, Bethesda, Maryland, USA). Steeg discussed her current work in understanding brain metastasis and the development of potential targeted therapies for this devastating condition [6,7]. Subsequently, there were original contributions on current novel studies of new targets in IBC. Zhaomei Mu (Fox Chase Cancer Center, Philadelphia, PA, USA) presented a preclinical study using the epidermal growth factor (EGF) family inhibitor AZD8931 against HER2-expressing IBC cells (SUM190) and EGF receptorpositive cells (SUM149) and the recently described FC-IBC-02. Naoto Ueno (MD Anderson Cancer Center, Houston, TX, USA) described his laboratory's work on the promotion of epithelial-mesenchymal and stem cell-like populations in EGF receptor-overexpressing IBC by COX-2 [8], indicating a potential therapeutic role for inhibitors of this pathway. Subsequently, Fredika Robertson (MD Anderson Cancer Center) described her work on anaplastic lymphoma kinase protein expression (without associated rearrangement) promoting the formation of intralymphatic tumor emboli [9]. The therapeutic targeting of platelet-derived growth factor receptor (PDGFR) $\alpha$ was the topic of Madhura Jogleka's presentation (University of Delaware, USA). Jogleka proposed this new modeling of lymphatic flow for the study of the migration of SUM149 identified PDGFR $\alpha$ overexpression as a critical pathway for disease progression and metastases in IBC [10]. Finally, Bedrich Eckhardt (MD Anderson Cancer Center) presented novel work using adeno-associated virus and M13 phage that display tumor-homing peptides to target IBC.

A concurrent session for nurses, allied health professionals and advocates was held and featured an overview of IBC past, present and future by Pam Alizadeh (MD Anderson Cancer Center). A panel discussion on the role of advocates in IBC research and education closed out the session.

The third session focused on evolving treatments for IBC, from bench to bedside. The opening plenary lecture was presented by Neil Spector (Duke Cancer Institute, Durham, NC, USA) and focused on evolving HER2targeted therapies in breast cancer with an emphasis on how they can be applied to IBC, which tends to be a Her2 expressing cancer [11]. Four abstracts were selected for oral presentation in this session. The first was presented by Hiroko Masuda (MD Anderson Cancer Center) and described a study determining the efficacy of neoadjuvant systemic therapy in estrogen receptorpositive versus HER2-positive IBCs. This study used a large cohort of 545 patients and determined that IBC patients that are estrogen receptor-negative and HER2positive benefited from neoadjuvant systemic therapy. Rachel Atkinson (MD Anderson Cancer Center) presented an elegant description of the epidemiological risk factors and normal breast tissue markers involved in IBC. She described a novel stem cell-like pattern unique to IBC, which was identified in all samples from 160 patients. The third abstract was presented by Fredika Robertson and represented an expansion of her work with anaplastic lymphoma kinase in IBC. In this presentation she demonstrated the prevalence of anaplastic lymphoma kinase pathway activation, which is associated with genetic changes in the gene. The final presentation was by R Katherine Alpaugh (Fox Chase Cancer Center) and described differences in genetic mutations between different tissue sources from the same patient. Next-generation sequencing was performed for 182 cancer-related genes on multiple tissue sources from 32 patients. This work concluded that sequencing to identify therapeutic targets should represent current disease [12,13].

The fourth educational session addressed unanswered questions on loco regional therapies. The plenary lecture was given by Wendy Woodward (MD Anderson Cancer Center) and addressed some of the evolving loco regional radiation therapies for IBC. One abstract was chosen for presentation in this session. $\mathrm{H}$ Carisa Le-Petross (MD Anderson Cancer Center, Houston, Texas, USA) discussed assessment of residual disease in IBC patients who received neoadjuvant chemotherapy, using mammography, ultrasound, and magnetic resonance imaging. The work determined that both ultrasound and magnetic resonance imaging are effective in determining residual disease in patients $[14,15]$.

The final session covered the handling, analysis and imaging of tissue in the laboratory. It opened with an invited lecture from Emanuel F Petricoin (George Mason University, Fairfax, VA, USA) on the use of protein microarrays for molecular diagnostics and therapeutic targeting [16]. Francois-Clement Bidard (Institut Curie, Paris, France) presented findings from the BEVERLY 01 and 02 trials focusing on the detection of circulating tumor cells and circulating endothelial cells in IBC patients [17]. These patients received neoadjuvant chemotherapy combined with bevacizumab and trastuzumab. Analysis found that circulating tumor cell and circulating endothelial cell levels dropped from baseline in both studies as a result of treatment.

The conference ended with a round table discussion including all of the conference participants. The discussion highlighted educational and research priorities in IBC. Specific priorities include rigorous epidemiological studies with a focus on environmental factors and further expansion of preclinical models supporting the rational development of dedicated clinical trials.

\section{Conclusion}

The intent of the third international IBC conference was to focus on new and upcoming areas of research, diagnosis and treatment in IBC. Several new areas of research focused on identifying novel molecular targets 
were presented, as well as new diagnostic methods and the results of new treatment modalities. Thus, this conference highlighted the significant progress that has been made in the IBC field over the past 2 years.

\section{Abbreviations}

EGF: Epidermal growth factor; IBC: Inflammatory breast cancer;

PDGFR: Platelet-derived growth factor receptor

\section{Competing interests}

The authors declare that they have no competing interests.

\section{Author details}

${ }^{1}$ Department of Biological Sciences, 320 Wolf Hall, The Center for Translational Cancer Research, The University of Delaware, Newark, DE 19716, USA. ${ }^{2}$ The Helen F Graham Cancer Center, 4701 Ogletown Stanton Road, Newark, DE 19713, USA. ${ }^{3}$ Department of Medical Oncology, Thomas Jefferson University, Kimmel Cancer Center, 1025 Walnut St-Suite 700, Philadelphia, PA 19107, USA.

Published: 05 Nov 2013

\section{References}

1. Dushkin H, Cristofanilli M: Inflammatory breast cancer. J Natl Compr Canc Netw 2011, 9:233-240.

2. Robertson FM, Bondy M, Yang W, Yamauchi H, Wiggins S, Kamrudin S, Krishnamurthy S, Le-Petross H, Bidaut L, Player AN, Barsky SH, Woodward WA, Buchholz T, Lucci A, Ueno NT, Cristofanilli M: Inflammatory breast cancer: the disease, the biology, the treatment. CA Cancer J Clin 2010, 60:351-375.

3. Dang CV: MYC on the path to cancer. Cell 2012, 149:22-35.

4. Duke TJ, Jahed NC, Veneroso CC, Da Roza R, Johnson O, Hoffman D, Barsky $\mathrm{SH}$, Levine PH: A cluster of inflammatory breast cancer (IBC) in an office setting: additional evidence of the importance of environmental factors in IBC etiology. Oncol Rep 2010, 24:1277-1284.

5. Schlichting JA, Soliman AS, Schairer C, Schottenfeld D, Merajver SD: Inflammatory and non-inflammatory breast cancer survival by socioeconomic position in the Surveillance, Epidemiology, and End Results database, 1990-2008. Breast Cancer Res Treat 2012, 134:1257-1268.

6. Liu H, Kato Y, Erzinger SA, Kiriakova GM, Qian Y, Palmieri D, Steeg PS, Price JE: The role of MMP-1 in breast cancer growth and metastasis to the brain in a xenograft model. BMC Cancer 2012, 12:583.

7. Fitzgerald DP, Emerson DL, Qian Y, Anwar T, Liewehr DJ, Steinberg SM, Silberman S, Palmieri D, Steeg PS: TPI-287, a new taxane family member, reduces the brain metastatic colonization of breast cancer cells. $\mathrm{Mol}$ Cancer Ther 2012, 11:1959-1967.

8. Zhang D, LaFortune TA, Krishnamurthy S, Esteva FJ, Cristofanilli M, Liu P, Lucci A, Singh B, Hung MC, Hortobagyi GN, Ueno NT: Epidermal growth factor receptor tyrosine kinase inhibitor reverses mesenchymal to epithelial phenotype and inhibits metastasis in inflammatory breast cancer. Clin Cancer Res 2009, 15:6639-6648.

9. Robertson FM, Petricoin, lii EF, Van Laere SJ, Bertucci F, Chu K, Fernandez SV, Mu Z, Alpaugh K, Pei J, Circo R, Wulfkuhlse J, Ye Z, Boley KM, Liu H, Moraes R, Zhang X, Demaria R, Barsk SH, Sun G, Christofanilli M: Amplification of anaplastic lymphoma kinase (ALK) as a common genetic alteration in inflammatory breast cancer. Springerplus 2013, 2:497.

10. Lehman HL, Dashner EJ, Lucey M, Vermeulen P, Dirix L, Van Laere S, van Golen KL: Modeling and characterization of inflammatory breast cancer emboli grown in vitro. Int J Cancer 2013, 132:2283-2294.

11. Johnston S, Trudeau M, Kaufman B, Boussen H, Blackwell K, LoRusso P, Lombardi DP, Ben Ahmed S, Citrin DL, DeSilvio ML, Harris J, Westlund RE, Salazar V, Zaks TZ, Spector NL: Phase II study of predictive biomarker profiles for response targeting human epidermal growth factor receptor 2 (HER-2) in advanced inflammatory breast cancer with lapatinib monotherapy. J Clin Oncol 2008, 26:1066-1072.

12. Cristofanilli M, Alpaugh KR, Ross J, Binghman $C$, Wu H, Stephens $P$, Lipson D, Palmer G: Next generation genomic sequencing (NGS) identifies molecular targets in inflammatory breast cancer (IBC). Cancer Res 2012 , 72. abstract PD5-01(124s).
13. Alpaugh RK, Bingham C, Fittipaldi P, Banzi M, Palmber G, Christofanilli M: What is the appropriate sample (s) on which to perform sequencing for mutational analysis to guide the selection of targeted therapy? Cancer Res 2012, 72. abstract PD5-03(125s).

14. Le-Petross HT, Cristofanilli M, Carkaci S, Krishnamurthy S, Jackson EF, Harrel RK, Reed BJ, Yang WT: MRI features of inflammatory breast cancer. AJR Am J Roentgenol 2011, 197:W769-W776.

15. Le-Petross H, Uppendahl L, Stafford J: Sonographic features of inflammatory breast cancer. Semin Roentgenol 2011, 46:275-279.

16. Sereni MI, Pierobon M, Angioli R, Petricoin EF 3rd, Frederick MJ: Reverse phase protein microarrays and their utility in drug development. Methods Mol Biol 2013, 986:187-214.

17. Pierga JY, Petit T, Delozier T, Ferrero JM, Campone M, Gligorov J, Lerebours F, Roché H, Bachelot T, Charafe-Jauffret E, Pavlyuk M, Kraemer S, Bidard FC, Viens P: Neoadjuvant bevacizumab, trastuzumab, and chemotherapy for primary inflammatory HER2-positive breast cancer (BEVERLY-2): an openlabel, single-arm phase 2 study. Lancet Oncol 2012, 13:375-384.

$10.1186 /$ bcr3571

Cite this article as: van Golen and Cristofanilli: The Third International Inflammatory Breast Cancer Conference. Breast Cancer Research 2013, 15:318 